\title{
Modeling network phenomena in the Inferior Olive: II. Modulation of sub-threshold oscillations
}

\author{
Benjamin Torben-Nielsen ${ }^{1,3^{*}}$, Yaara Lefler ${ }^{1}$, Idan Segev ${ }^{1,2,3}$, Yosef Yarom ${ }^{1,2,3}$ \\ From Twentieth Annual Computational Neuroscience Meeting: CNS*2011 \\ Stockholm, Sweden. 23-28 July 2011
}

Sub-threshold oscillations (STOs) provide a timing signal for the Inferior Olive (IO) neurons as IO cells are known to fire only phase-locked to the peak of the STO. Moreover, based on in-vitro and in-vivo experiments, it has been proposed that the STOs are actively modulated to represent spatiotemporal patterns [1,2]. Modulations are manifested in changes in frequency and amplitude, and a stable phase-shift between different clusters to accommodate for timing signals with a higher temporal resolution than the period of the oscillation [3].

In this work we investigated how STOs can be dynamically modulated. To this end we simulated networks of canonical IO neurons including a low-threshold $\mathrm{Ca}^{2+}$ current and a leak current. In isolation, these cells can generate spontaneous oscillations at different frequencies $(4-17 \mathrm{~Hz})$ for particular densities of the associated $\mathrm{g}_{\mathrm{Ca}}$ and $\mathrm{g}_{\mathrm{L}}$ conductances [4]. When coupled through gapjunctions, a population of such neurons with heterogeneous densities of $g_{C a}$ and $g_{L}$ will -in general- exhibit spontaneous STOs as long as the "average cell" (i.e., a weighted average of the conductances of all connected cells) would be a spontaneously oscillating cell. Thus, in theory, the frequency of the oscillations can be directly modulated by changing the "average cell", i.e., by manipulating the contributions of each cell to the "average cell". In practice, the contribution of a cell is related to the coupling strengths to other cells. Hence, increasing and decreasing the coupling strength between cells changes the "average cell" and causes a change in frequency of the STOs. We simulated networks with a realistic number of cells (for a given amount of tissue) and changed the coupling strengths during the simulation.

\footnotetext{
* Correspondence: btorbennielsen@gmail.com

† Contributed equally

${ }^{1}$ Edmond and Lily Safra Center for Brain Sciences, Hebrew University, Jerusalem, Israel

Full list of author information is available at the end of the article
}

In some cases we simulated a complete decoupling between different parts of the network. We found that for a range of realistic coupling strengths we could reproduce two experimental observations: Sudden jumps in STO frequency between $6-12 \mathrm{~Hz}$, and, stable phase-shifts of up to $30 \mathrm{~ms}$ between (self-organizing) clusters within the simulated networks.

We argue that the GABAergic inputs from the deep cerebellar nucleus (DCN) are well suited to adjust the coupling strength as they are known to shunt gap-junctional currents when activated. Also, we speculate that the stable phase-shift between clusters causes the observed "waves" of activation in IO neurons [1]. An alternative mechanism that can modulate the STO frequency is based on activitydependent changes in the $\mathrm{Ca}^{2+}$ driving force which we found to affect the frequency of the STO in simulations. We conclude that changing the coupling strengths of the network by GABAergic inputs from the DCN is a plausible mechanism to actively modulate spatiotemporal patterns.

\footnotetext{
Acknowledgements

This research is partially supported by a FP7 People Initial Training Network Grant, Grant number: PITN-GA-2009-238686 (CEREBNET).

Author details

${ }^{1}$ Edmond and Lily Safra Center for Brain Sciences, Hebrew University, Jerusalem, Israel. ${ }^{2}$ Interdisciplinary Center for Neural computation, Hebrew University, Jerusalem, Israel. ${ }^{3}$ Department of Neurobiology, Hebrew University, Jerusalem, Israel.

Published: 18 July 2011
References
1. Devor A, Yarom Y: Generation and propagation of subthreshold waves in a network of inferior olivary neurons. J Neurophysiol 2002, 87:3059-69.
2. Chorev E, Yarom Y, Lampl I: Rhythmic episodes of subthreshold membrane potential oscillations in the rat inferior olive nuclei in vivo. J Neurosci 2007, 27:5043-52.
3. Jacobson GA, Rokni D, Yarom Y: A model of the olivo-cerebellar system as a temporal pattern generator. Trends Neurosci 2008, 31:617-25.


4. Manor Y, Rinzel J, Segev I, Yarom Y: Low Amplitude Oscillations in the Inferior Olive: A model based on electrical coupling of neurons with heterogeneous channel densities. J. Neurophysiol 1997, 77:2736-2752.

doi:10.1186/1471-2202-12-S1-P380

Cite this article as: Torben-Nielsen et al:: Modeling network phenomena in the Inferior Olive: II. Modulation of sub-threshold oscillations. BMC Neuroscience 2011 12(Suppl 1):P380.

Submit your next manuscript to BioMed Central and take full advantage of:

- Convenient online submission

- Thorough peer review

- No space constraints or color figure charges

- Immediate publication on acceptance

- Inclusion in PubMed, CAS, Scopus and Google Scholar

- Research which is freely available for redistribution

Submit your manuscript at www.biomedcentral.com/submit 